\title{
Time to Conduct Community-Oriented Researches in Geriatrics
}

Geriatric medicine is a specialty that focuses on medical issues among older adults with low physical function. We are investigating changes in humans with aging and agerelated pathologic process and are identifying patterns and rules that are different from those of young individuals. This involves not only biological factors but also various social determinant factors. For example, increased body weight among older adults could cause degenerative changes in lower articular cartilages. Although the diagnosis is as simple as arthritis, if it is combined with social frailty (e.g., lack of social support), it could deteriorate the function of the lower extremities and result in an individual being homebound. It is difficult for individuals who are homebound to use medical services for treating arthritis and/or other health problems all by themselves. As a result, the vicious cycle of homebound state and frailty will aggregate the health condition of older adults: decreased physical function $\rightarrow$ homebound state $\rightarrow$ unmet healthcare needs $\rightarrow$ decreased physical function $\rightarrow$... Thus, if we do not figure out the whole reasons of homebound state, the physical function of individuals who are homebound may not be completely restored even with the treatment of arthritis. From a gerontological point of view, homebound state is significantly associated with the concept of Aging in Place (AIP). AIP is defined as the ability to live in one's own home and community safely, independently, and comfortably, regardless of age, income, or ability level.

Since 1968, the establishment of the Korean Geriatric Society in Korea has been making remarkable progress over 50 years. However, only few studies in which were comprehensively reviewed in the context of homebound state or AIP have been conducted. Although the novel concept of frailty has been actively investigated for the last 15 years, it has still been described in terms of physical frailty or sarcopenia on the basis of biomedical perspective. However, ironically, community-dwelling older adults seldom use the term frailty to describe themselves or their conditions. ${ }^{1,2)}$ According to qualitative studies on patient-centered perspective, being at home is more than occupying a physically familiar space; i.e., it is an anchorage to prior frequently habituated places. ${ }^{2}$ Therefore, we must provide careful consideration in deciding what place is more appropriate in diagnosing and treating older adults. Particularly, in the case of frail older adults, unnecessary admission to an acute care unit (i.e., hospitalization) may remarkably aggregate health conditions due to immobility syndrome. In some cases, disease may be cured. However, physical function might not be restored. Thus, the organization of healthcare is one of the outmost important issues in the field of geriatric medicine.

Will homebound state, AIP, or organization of care be the important issues of geriatric medicine in Korea? I think they will be soon. In Korea, The Plan for Community Care has been introduced in June 2018, and several ambitious projects have been initiated by the Ministry of Health and Welfare. The Plan for Community Care is a novel system in which residents who need care can continue to lead a life in the community, such as home or group homes, and receive sufficient health and welfare services. Among the topics for healthcare action, there are noteworthy plans (1) to strengthen the community-based healthcare system, (2) to support settlements of individuals who need care, and (3) to encourage the rational use of hospitals and long-term care facilities. More specifically, pilot projects, such as (1) the homebased hospice pilot project (until August 2018), (2) pilot project of healthcare physician for the disabled (until April 2019), and (3) house call project for the severely ill pediatric patients (from September 2018), are being planned or initiated. These pilot projects are expected to be disseminated to community-dwelling older adults, particularly those who are in homebound state. Then, physician's home visit will be more frequent than before.

What issues should be pursued in the policy environment of the Plan for Community Care?

(1) Social determinants of health in microlevels, such as self-efficacy, social network, and social engagement

(2) Social determinants of disability in meso-levels, such as neighborhood characteristics

(3) Organization of healthcare, such as transitional care, home visits, assisted-living facilities, group or foster homes, and continuing care retirement community

Regarding the issues about the organization of care, the systems of healthcare in Korea may not be optimal for the treatment of chronic illness among community-dwelling older adults. Several models of acute care system are available in Korea. However, the care systems for subacute and long-term care for older adults are limited. Recently, Korea is more likely to concentrate on nursing home and long-term care hospitals for impaired older adults rather than a continuum of sheltered housing environments or community-based care. However, a contemporary discussion of long-term care is more likely to emphasize alternatives to institutionalization and home- and community- 
based care. ${ }^{3)}$ For example, in the United States, various models of community-based long-term care, such as the Program of All-inclusive Care for the Elderly, Home Based Primary Care, Adult Day Health Care, and social health maintenance organization, have been investigated and virtually operated. ${ }^{4,5)}$ These models have something in common. That is, they follow the AIP philosophy. Canada and some countries in Western Europe, which include long-term care as a basic component of their national health financing system have expanded consumer directed care models rapidly. In this model, homecare recipients can choose to hire and pay their family members to provide community-based long-term care services with state funds. ${ }^{5}$ One thing seems to be certain, to make these alternative structures, we have to think more deeply and concentrate on the psychosocial aspect of aging.

In addition, the physician's role in homecare setting will be different from that in the hospital. In community-based long-term care setting, the physician must provide ongoing medical services, coordinate activities of the interdisciplinary team, and serve as an advocate for patients. In addition, home visits may reveal new problems, such as use of multiple drugs, nutritional deficits, depression, living alone, insufficient caregiver, and unhealthy lifestyle. More complicated problems (e.g., care of dying patients, mistreatment of elderly individuals, decisional capacity, informed consent, surrogate decision making, and advance care planning) should be re-examined in homecare setting. It will be a new challenge that has not been experienced before.

Thus, the Plan for Community Care that was introduced by the Korean government will provide both opportunities and challenges to geriatricians. New unpredictable issues that have only been observed in hypothetical theories may arise. However, if we take these as opportunities to significantly improve geriatric medicine in Korea, there are too many themes to conduct community-oriented researches in the future. In particular, efforts in identifying an alternative care system that is appropriate to the policy environment in Korea should be continued over the next 10 years. In relation to this, homebound older adults can demand a physician to come to their house as a social right. This will be the greatest challenge for geriatricians in the near future. However, this will clearly portray the right to health of older individuals. I hope that such meaningful efforts can be initiated by the Korean Geriatric Society and be published in the Annals of Geriatric Medicine and Research.

Chang-0 Kim, MD, MSW Associate Editor https://orcid.org/0000-0001-5858-4529 Institute of Social Welfare, SungKongHoe University, Seoul, Korea

E-mail: nation@skhu.ac.kr

\section{REFERENCES}

1. Schoenborn NL, Van Pilsum Rasmussen SE, Xue Q, Walston J, McAdams-Demarco MA, Segev DL, et al. Older adults' perceptions and informal needs regarding frailty. BMC Geriatr 2018;18:46.

2. Nicholson C, Meyer J, Flately M, Holman C, Lowton K. Living on the margin: Understanding the experience of living and dying with frailty in old age. Soc Sci Med 2012;75:1426-32.

3. Glass TM, Maddox GL. Psychosocial aspect of aging. In: Hazzard WR, Blass JP, Halter JB, Ouslander JG, Tinetti ME. Principles of geriatric medicine and gerontology. 5th ed. New York: McGrawHill; 2003. p. 77-84.

4. Kim CO, Jang SN. Home-based primary care for homebound older adults: Literature review. Ann Geriatr Med Res 2018;22:62-72.

5. Leff B. Community-based long term care and home care. In: Hazzard WR, Blass JP, Halter JB, Ouslander JG, Tinetti ME. Principles of geriatric medicine and gerontology. 5th ed. New York: McGraw-Hill; 2003. p. 211-7. 